\title{
Rhetoric, Argumentation and Logic
}

\author{
George Yoos
}

St. Cloud State University

Fundamental to a rhetorical situation is an invitation. Rhetors do not force themselves on audiences. Audiences give their attention. Authors accept that attention. I see myself here talking to you as part of such an invitation. Speakers and writers address situations ripe with invitations, not only formal and explicit invitations, but ones generated by exigencies in rhetorical situations. Moreover, they may address their audiences through bonding and advertisement to gain attention and interest. Listeners and readers, in an extended sense of the term "invitation," invite speakers and writers to continue saying what they have to say. It is key to rhetoric to make maximum usage of the allotted entitlement generated by this invitation to fulfill rhetorical aims and purposes of the rhetor.

What I am particularly interested in is how in cooperative transactions audiences confer on speakers and writers by invitations entitlements to engage in various sorts of rhetorical appeals. Let me put aside spoken appeals. I want to confine my interest to rhetorical entitlements conferred by readers of written rhetorical appeals, for I am particularly interested in the perception, analysis, and critical assessment of rhetoric and logic in reading, especially in the reading of extended types of discourse where functional prose is a cooperative transaction taking place between writer and reader.

Two points of view are of special interest in the reading of extended discourse. First there is the perception of the deployed rhetorical strategies employed by the writer, especially those strategies displaying for rhetorical purposes strict entailments and evidence for contentions and hypotheses. The perception of the reader in this first case is directed towards the writer's logic embedded in his rhetoric. The second role of the reader attends not only to the writer's role but to the reader's own inferential processes in interpreting what the writer is trying to do and say in a text. Readers form hypotheses about what is going on in a text. Readers need to assess their own reasons and evidence warranting their interpretive hypotheses. There is thus a twofold attention to logic in reading, first to the writer's logic and second to the reader's own logic in interpreting the writer's logic.

The writer's logic needs to be understood in a framework of entitlements and presumptive rights that authors exercise in addressing their audiences. What I want to show is that a great deal of our understanding of what goes wrong in argumentation and in explanation needs to be diagnosed in term: of the context of discourse and in terms of the re. $\mathrm{OE}$ nized conventions of different sorts of communic ative situations. What is good and bad about argt: ment and explanation needs to be assessed within the framework of rhetorical strategies, and not yst simply from any display of logical connections, ween statements.

If as I maintain there is such a close and intiriat. connection between rhetoric and logic, how is it that the academic disciplines of rhetoric and lugic have since the time of Aristotle gradually drawr: apart as disciplines? Hamblin in Fallacies interestingly notes that after Cicero the topic of fallacies separated from rhetoric. It is also interesting to note that by the 16th and 17th centuries fallacies were treated not as sophisms or deceptions but as mental 
errors or mistakes. A much more dramatic divorce occurred when Peter Ramus in the 16th century separated much of the core of rhetoric that centered on argument from rhetorical studies by placing invention and arrangement in logic, thus leaving only the topics of eloquence and style to rhetorical studies. As logical studies moved in the direction of epistemological questions, logic historically continued to separate its ties with communications studies. A quick glance at the etymology of logical jargon betrays the past historical ties of logic to discourse processes. Note "reasoning with," "arguing for," "maintaining," "contending," "warranting," "demonstrating," and "implying," are all discourse processes. Logic today primarily deals with normative questions, such as validity and soundness in making inferences, and not with the production of effective strategies for communication and persuasion. Rhetoric. on the other hand, today focuses on the psychological processes of persuasion. It focuses on the art of making effective and persuasive appeals through discourse strategies. But in focusing on the psychological aspects of using discourse, contemporary rhetorical studies fail, in my view, to assess how logical forms and terms are integrated into the forms and structures of rhetorical appeals

I have observed in those teaching communication skills a general lack of appreciation of the value of informal logic for the improvement of such communication skills as writing, speaking, listening, and reading skills. In part this generalization, as I see it, is reinforced by the prevalent view coming from philosophy that logic improves thinking skills and that informal logic teaches critical thinking which superficially is not a communications skill. But it is my view that critical writing and critical reading are pretty much the same activity as critical thinking, and that critical thinking is reflected in and through critical writing and reading. Critical thinking is, I contend, known through language behavior.

A careful analysis of rhetorical theory casts a great deal of light on how logical argument integrates into the structure of rhetorical appeals. The popular perception of rhetoric as essentially a pejorative activitv, ignores the notion. as it does for Aristotle. that an errective rnetoric is one that provides good ariu valid reasons for its contentions. Moreover, the popular perception of rhetoric also does not include a view held by writing teachers about rhetoric, the notion that effective rhetoric is the art of fashioning clear, concise, and precise communications. Rhetoric among composition teachers facilitates reading and comprehension. Rhetoric, therefore, is as concerned as is logic with sound argument and explanation. But in what way do the concerns of rhetoric and logic differ? In what ways do they overlap? A quick survey of the use of the terms "argument" and "explanation," as I hope to show, helps us see how rhetoric and logic play an integral role in effective communications.

1 identify four senses of argument. There is a sociological or a political sense of the term in which to argue is to engage in controversy, quarrel, conflict, or where there is danger, threat and violence. The sense of the term argument as controversy is pejorative: such arguments are socially disruptive and bad. A second sense of the term argument is found in Speech Communications. It is the rhetorical sense of the term. Arguments are rhetorical appeals. They are suasory appeals, attempts to alter attitudes and beliefs of others. Rhetorical arguments try to alter attitudes and beliefs, and try to effect human decisions and actions. They attempt to effect change by appealing to the feelings, attitudes, beliefs, and the concessions others are willing to make to a speaker. Rhetorical arguments very often appear to be pejorative in that rhetoric is ad hominem in the appeal to the prejudices of audiences, to their emotions, and to their willingness to be misled by the charisma of speakers. Rhetoric in this sense appears pejorative in that it manipulates and exploits ignorance.

You are well aware of the third sense of argument. It is the sense found in deductive logic. Deductive logic is concerned with the basis of strict entailment, that is, whether or not there is a necessary connection between the truth values of one statement, or a set of statements with another. Rhetorical arguments as such are not necessarily deductive arguments and deductive arguments are not necessarily rhetorical arguments. Explanations may be deductive arguments, and arguments from hypotheses are also deductive. Thus, rhetorically deductive arguments mav be integrated into rhetorical appeals, into theoretical and causal explanations or into exploratory discourse where, in each case, a writer is trying to show what follows from what.

A fourth sense of argument, as again you well know, is found in inductive logic. Inductive argument is the study of the degree to which observed evidence or date warrants the likelihood or probability of statements of what is not open to observation: about the past, the future, or what is presently not open to observation. In other words, inductive arguments are never final or closed in the sense that possible disconfirming evidence is ruled out. They are not warranted by any notion of logical necessity.

Thus, we can argue or quarrel without trying to argue rhetorically, without appealing to deductive or inductive arguments. One can argue rhetorically without utılizing deductive and inductive arguments. Rhetorical arguments, as already mentioned, may be based upon appeal to attitudes in the audience towards the speaker (ethos) or to the feelings or values within the audience (pathos). Deductive argu- 
ments are used independently of inductive arguments and vice-versa. However, the four senses of argument can be integrated in that we can in arguing (controversy) argue rhetorically using both deductive and inductive arguments. Moreover, rhetorical arguments need not address conflict situations. They may positively address situations ripe with opportunities. On the other hand, logical arguments, deductive and inductive, are used in other modes of discourse besides rhetorical argumentative discourse. Deductive arguments occur in explanations. They occur in displays of the logical connections between statements that usually occur when an author tries to show someone the logical implications between statements or the evidential relationships between statements. Logic then may not be a part of rhetorical argument, but on the other hand, it frequently carries the full weight and force of rhetorical argument. I want here simply to refer to my schema of the grammar of rhetorical argumentative structure riding on the logical structure of argument, what I call the Piggy Back Grammar of Rhetorical Logical Appeal. (See Figure 1.)

If we turn now to the role logic plays in other modes of discourse, it is of interest to reflect on Alexander Bain's four modes of discourse: narrative, description, argument and exposition. Historically, narrative and description have been the primary modes of literary discourse, while functional prose has for the most part been reduced to exposition, as argument has been perceived to be a form of exposition. Interestingly, Speech Communications has focused on argumentation as a field of study, while College Composition has focused on processes of exposition. Although Bain's taxonomy has been considered useless and misleading by many rhetoricians, yet these modes of discourse, as I want to show, do in part reflect quite well the developmental strategies that carry out the overall text commitments, aims and strategies of authors, especially as they are carried out in writing at the paragraph level. What makes talk about modes confusing is that Bain's categories conflate a number of distinct senses of the terms used in his taxonomy, as illustrated already in the above discussion of senses of the term 'argument.' Moreover, what adds to the confusion is that these modes are interactive. For example, in exposition we might give theoretical explanations for certain types of occurrences, using deductive and inductive arguments to develop and justify our explanations, while at the same time we also illustrate our explanations with examples using either description or narration. In other words, we might employ all Bain's modes at different stages of what we are doing in a piece of discourse.

Let me now try to unpack what is conflated under an expository mode. Webster's Collegiate Dictionary defines "exposition" as "discourse, or an example of it, designed to expound, explain, or appraise analytically." All three terms - "expound," "explain," or "appraise" -indicate discourse that involves warrant and judgment. These processes overlap with processes of argument already discussed and outlined. Consequently, argument as a mode of discourse (as already mentioned) tends to disappear as a category in composition studies and becomes a subspecies of exposition. My strategy in discussing these processes is to divide exposition into two sets of processes, called "argument" and "explanation." What is important in the rhetorical use of modes is to trace the various types of interaction between processes of argument and explanation. These interactions are quite complex, and I cannot do more here than to outline the variety of senses of "explanation" that I have sought to identify.

Let me list fifteen senses of "explanation" that I have identified and labeled. (See Figure 2.) My list

\section{Types of Explanation}

1. of a process

2. of someone else's motives or purposes

3. by giving physical cause

4. by a directly testable hypothesis

5. by an indirect hypothesis

6. by a systematic theory

7. of what someone else is saying

8. of an historical event

9. of a problem

10. of one's own purposes or motives

11. of meaning of what one is saying

12. of what one is doing

13. of a conceptual scheme or model

14. of a visual scheme or model

- technical

- teleological

- causal

- empirical generalization

- theoretical

- systematic theoretical

- interpretive

- historical

- problematic

- of one's own aim or purpose

- semantic clarification

- pragmatic clarification

- conceptual

- of visual illustration

15. of reasons for acting in terms of rules or principles
- deontological 
RHETORICAL AND LOGICAL TERMS IN PIGGY BACK GRMPAR OF RIETORICAL LOGICAL ARGURENT

D1scourse Acts Lay the Foundations of Argument

A. Polnts No longer at Issue

$$
\text { Acceptance }
$$

since $p$ and $q$ and...

B. Statemente Considered for Bearinge On othera

and therefore

If we accept $p$ and $q$ and...

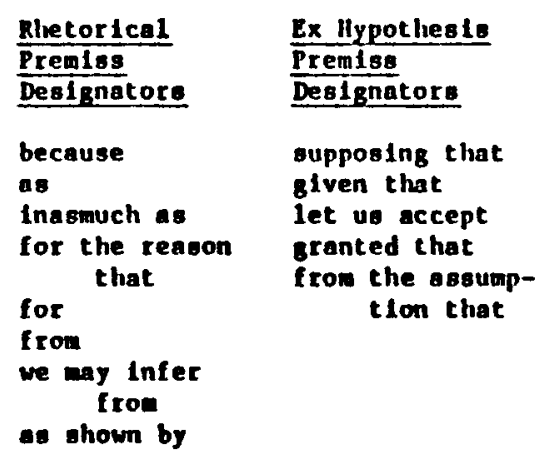

\begin{tabular}{l} 
Premise \\
Reference \\
\hline Designators \\
from the fore- \\
going \\
hence \\
thus \\
consequently \\
so follows \\
It follows \\
that \\
we may argue \\
that \\
we may conclude \\
that \\
leads us to \\
accept that \\
slows that \\
demonstrates that \\
supports the \\
conclusion \\
that \\
proves that
\end{tabular}

proves that
Appeal for Acceptance

Polnt at Is oue

necessar1ly

1t probably follows

that it is true

that $C$

18 true

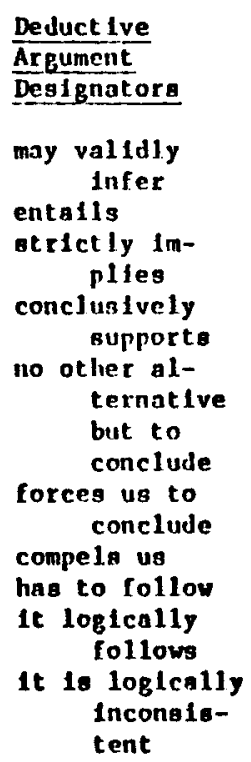

\section{entails}

Valid Rules of Inference

\begin{tabular}{ll} 
Inductive & Rhetorfcal \\
\hline Argument & Acceptance \\
DesIgnators & Value
\end{tabular}

conflrms

oupports

evidently

rellable

probably

\begin{tabular}{|c|c|}
\hline $\begin{array}{l}\text { Modalite } \\
\text { statement }\end{array}$ & Statement \\
\hline Verbs & Value \\
\hline $\begin{array}{l}\text { ought } \\
\text { will be } \\
\text { lg }\end{array}$ & $\begin{array}{l}\text { is good } \\
\text { is right } \\
\text { is correct }\end{array}$ \\
\hline
\end{tabular}

most likely

predictable

Inconclusively

reinforces

suatalns

it is right

it 1 s good

it is correct

It 18 probably

tt is posstble

it is 11kely

It is legal

it is rellable

It 18 clent

it 18 bellev-$$
\text { oble }
$$

it 18 permis-

sible

1t 18 under- might be

could be

Is correct

\section{Figure 1}


makes no pretense of being exhaustive and nonoverlapping. But my list does serve the purpose of illustrating where logic, rhetorical argument, and providing explanations overlap and interrelate. It is noteworthy that some explanations on occasion require justification, and consequently in that case there develops the presumption that arguments are required and writers are not entitled to present such explanations without rhetorical argument. Other types of explanation, such as theoretical explanations, may embody deductive arguments. Finally, some types of explanation, such as those an author might provide in explaining such things as what he is saying, his use of language, his conceptual schemes, his illustrations, or his motives, do not require justification, logic or rhetorical argument. Thus, we see that rhetorical argument and explanations as modes of discourse interact in complex ways. Authors are governed by certain presumptions about what it is proper and necessary to do in using these modes of discoursing properly. An author's entitlements are thus constrained as to how these modes can be properly developed and carried out to fulfill the demands and expectations of his readers.

In the presentation of rhetorical arguments and in providing explanations writers operate within a pattern of constraints. Audiences require certain modes of presentation of premises or displays of explanation. Writers in turn may operate under various misconceptions about the real demands and expectations of audiences on how these rhetorical processes are to be presented. Writers thits inay have faulty presumptions about what is expectest or required of them in the way they present arguments and explanations. They may be mistiken a! out their entitlements.

Let me illustrate in some detail some entitlements writers have in laying the foundations of rhetorical logical argument. And in turn I shall give some examples of faulty presumptions writers may hold in presenting rhetorical logical arguments. Rhetorical logical arguments lay a foundation of statements in the audience by alerting the audience to the fact that the foundation is within the audience's knowledge base. Writers need to make their audiences fully aware of the foundations of their appeals in what they accept or in what they are willing to accept.

Basically there are three levels of awareness in audiences of what they hold and accept, or are willing to accept, coming out of their experiences. First, there are those matters of which audiences are fully aware and which audiences directly perceive as relevant to the issues and problems at hand. Writers do not need in such cases to mention to audiences what audiences are already fully aware of. Second, there are those matters of which audiences are peripherally aware, but matters which are dis- attended or held back in memory. Writers need therefore to redirect attention or jar the memory of their audiences by reminders. One major task in rhetorical logical argument is to bring disattended matters to full attention and to bring into focus the beliefs and experiences necessary to lay the foundation for an appeal. Basically, then, writers remind audiences of things that are not there immediately in their awareness, matters in the back of their mind, or at the periphery of their attention. Third, writers need sometimes, in laying the foundations of appeals, to direct the attention of audiences to aspects of experience of which they are not now nor have been aware, but which audiences will notice if their attention is directed in a proper manner. Writers utilize all sorts of ploys to get audiences to note things from different perspectives. Analogies and figurative language are useful to get audiences to see things differently. Thus, there are three levels of directed perception used in the rhetoric of laying the foundations of argument in audience acceptances. There is the level of presupposed awareness, the level of disattended awareness, and the level of no awareness of potentially perceptible or noticeable aspects of experience. (I take Wittgenstein's discussion of the dawning of an aspect, which he illustrates using the duck-rabbit drawing, to be addressed to the third level. Cf.PI, IIxi, 194e.

There are two modes of rhetoric which do not utilize speech acts (that is, not simply speech acts) that lay the foundations of rhetorical argumentative appeals. First there are lines of presentation of argument for which, given the knowledge background and experiences of the audiences, there is no need to mention what is at the basis of argument. The foundation is simply understood by the audience in the context of the argument. The second mode is that of simply utilizing other rhetorical arguments considered persuasive to lay the foundations of argument. In other words, the writer uses rhetorical appeals presumed to be persuasive.

The remaining ways of laying the foundations of rhetorical argument in audience acceptance center on how speech acts focus audience awareness on their knowledge, beliefs, and experiences. First there is the speech act of reminding. Wittgenstein's Bemerkungen seem to be a mixture of reminding and noting. There is an important difference between the two acts that some philosophers fail to distinguish. Reminding brings disattended matters into focus as a basis of appeal, while noting is rhetorically brought about by generating new perspectives and frames for experiences. In noting there is awareness of something not previously present to awareness, something unnoticed. The duck was not seen to be a rabbit. There has been a shift in attention, a new realization, "a dawning of an aspect." 
A third mode of presenting premises is testifying. Testimony rests on presumptions of credibility and the conventions of acceptance of testimony. A fourth speech act used to lay the foundations of what an audience is willing to accept for purposes of argument is assuring. Assuring as a mode of presenting premises rests on the presumptions of one's own expertise in the eye of the audience. Essential to the rhetorical effectiveness of assurances is an accurate estimation of the entitlement an author has to give certain sorts of assurances. A fifth speech act used in presenting acceptable premises to audiences is citing testimony. Citing testimony rests upon presumptions of credibility of both writer and the cited author. Contextually and audience-wise, citing testimony is a relatively weak mode of laying down a basis of acceptance for argument in an audience. Finally, a sixth speech act for presenting premises that an audience is willing to accept is the reporting of the expertise of others. Again the basis of the appeal depends upon the audience's knowledge and beliefs about the expert and his, or her, reported expertise. With some audiences, testifying, assuring, citing testimony, and most of all reporting expertise of others, may require argument to lay the basis of any entitlement to present premises by these modes of speech acts. In other words, for audience acceptance of premises not directly in the audience's frames of experience, there needs to be a justified presumption of entitlement or an argued for basis for entitlement when laying the foundations of rhetorical argument.

What then is the relevance of the above-outlined strategies for laying the foundations of rhetorical appeals to problems about fallacies in informal logic? What I want to demonstrate specifically is that writers who violate presumptive entitlements are guilty of many of the standard traditional fallacies. In other words, authors who are too presumptuous about their entitlements violate acceptable modes of making rhetorical appeals. Many fallacies are not just simply violations of rules of inference or rules of evidence, but they are in actuality violations of what are acceptable modes of procedure in laying the foundation of acceptable arguments. Simply put, these authors are out of order in what they are doing or saying.

If we go over each strategy just enumerated for laying the foundation of argument, we find that each strategy can misfire and consequently be ineffective. Readers may not note a faulty presumption of entitlement and may fail to note that writers are not doing what they are doing correctly or legitimately, in which case writers suffer no handicap and their error goes undiscovered. But such writers are vulnerable in so far as any counter argument can bring the writer's faults to the attention of a reader. Thus, exposing faulty presumptions is an effective mode of undermining someone's argument.
A writer who rests an appeal on presumptive presuppositions not held by the audience is guilty of unwarranted presuppositions. Audiences usually detect unwarranted presuppositions in so far as they see that there can be no validity to the writer's argument without the presupposition. Second, laying the foundations of argument by argument is susceptible to the whole range of errors and mistakes in argumentation. But looking at the matter rhetorically, there is the possible faulty presumption of thinking that one's arguments, since they are logically sound, must be persuasive. Unfortunately, some people are not persuaded by logically sound arguments. Surely we all have had the experience of having sound arguments rejected. We might in such a case take the old Aristotelian adage as consolation, namely that it is demeaning to argue with certain people. But such comfort does not eliminate the fact that we need sometimes to argue with fools.

If we turn to the speech acts enumerated, each has different felicity conditions that make it appropriate, and when absent, make it go wrong or misfire. Reminding can go wrong in the same way as unwarranted presuppositions. In such cases reminders appear simply to be mere assertions. Faulty reminders appearing to be mere assertions are sometimes referred to as the fallacy of alleged certainty. In my experience alleged certainty is probably the most commonly used deceptive ploy. But what is called alleged certainty may have other motivations. For example, some writers are too presumptuous about their credibility and authority with some audiences, in which case they appear to be alleging what ought to be argued for. But mostly faulty reminders are based simply on faulty presumptions about what an audience knows and believes. In this case it is simply the rhetorical mistake of not knowing one's audience very well.

In noting, we may err in thinking that what we note is open to intersubjective confirmation. We thus may be too presumptuous in thinking that aspects of our experience are objectively verifiable when in fact they are mere subjective impressions. Noting is also peculiarly subject to misfires, for audiences may be too quick in judging acts of noting as false and in thinking that the author's remarks are a result of subjective impressions, when in fact the problem may be rhetorical failure to get someone to note something. It is extremely difficult to convince someone that they have failed to note something. Only after we have noted something do we realize that we had originally failed to note it.

A presumption of credibility is necessary for the effective use of testimony. Rhetorically one does not usually openly argue for one's own credibility. In certain contexts there is danger in being too presumptuous about one's entitlement to give testimony. Moreover the value of testimony is usually 
inversely proportional to the importance of the issue being argued about. Consequently, testimony, if important, usually needs to be confirmed. In order to avoid being too presumptuous about the value of their testimony, writers often hedge it to avoid the appearance of being too presumptuous about their credibility. In other words, mock modesty is sometimes effective in feigning credibility.

However, assuring, when hedged, appears to lack assurance. Confidence in one's authority is necessary for the appearance of authority. On the other hand, a faulty presumption of authority is not granted to writers with the same generosicy that people grant credibility. Moreover, if we argue for our own expertise, we need to do it quickly aind tactfully, avoiding being defensive about it. Ethica! appeal as a mode of appeal rests upon the ethos of the writer. It takes time to establish ethos. Thus one's standing with an audience is something that one can be easily mistaken about. Consequently, a faulty presumption of expertise is an easy mistake to make, especially when one is inclined to think well of oneself.

Citing the testimony of others is rhetorically a weak way of laying the foundation of an appeal. In law it is hearsay. In so much as testimony is weak evidence, one should not presume that its effectiveness is very high. In so much as giving testimonyeither one's own or that of other-is often given simply to illustrate a point, we need be very careful in using testimony as a basis for argument. Citing testimony is rhetorically more useful for illustration and example than argument.

Finally, reporting the expertise of others is something we may argue for. In other words, there needs to be a careful assessment of any presumption that we need not argue for the expertise of others. Unreliable authority arises from a poor assessment of how high an authority's standing is with the audience.

In summary, authors are entitled to lay the foundations of arguments in the above enumerated ways. Each mode of presentation rests upon an entitlement to perform each mode in a correct and felicitous way. The writer builds a foundation of argument in modes acceptable to audiences. The writer is entitled to certain presumptions based upon what he thinks an audience accepts or knows. In working to call attention to this framework of acceptance and knowledge, the author may be too presumptuous about it. He can make mistakes. He can perform speech acts in infelicitous and inappropriate ways that destroy his rapport and ability to relate and communicate with his audience. In short, he destroys the very foundation of his appeal in being too presumptuous about his entitlements.

Professor George Yoos, Department of Philosophy, St. Cloud State University, St. Cloud, Minnesota, 56301. 